\title{
Novel digitally-manufactured wooden beams for vibration reduction
}

\author{
C Málaga-Chuquitaype ${ }^{\mathrm{a}, *}, \mathrm{~J} \mathrm{Ilkanaev}^{\mathrm{b}}$ \\ ${ }^{a}$ Department of Civil and Environmental Engineering, Imperial College London, UK \\ ${ }^{b}$ Happold Ingenieurbro GmbH, Berlin, Germany
}

\begin{abstract}
The low modal mass and stiffness of timber floors impose a number of motioncontrol challenges to the structural designer. These difficulties can often led to the implementation of sub-optimal solutions, such as the addition of supplemental mass and stiffness in the form of concrete slabs, that conflict with the claimed sustainability and lightweight advantages of wood. In this paper, we present a novel beam configuration that enhances the vibration comfort response of timber flooring systems while retaining the original environmental benefits of wood in construction. By taking advantage of modern digital-fabrication tools, we devise, test and analyse new beam configurations that incorporate flexural resonators tuned to key structural frequencies of the system. These resonators are integrated into the body of the beam and the structure is sized to satisfy typical strength and stiffness demands. A series of numerical, experimental and parametric studies demonstrate the vibration absorbing capabilities of the new designs and the feasibility of their implementation to satisfy current occupant comfort criteria.
\end{abstract}

Keywords: building occupant comfort, wood, 3D printing, testing, band-gap structures

\footnotetext{
* Corresponding author

Email address: c.malaga@imperial.ac.uk ( C Málaga-Chuquitaype)
} 


\section{Introduction}

Advances in building construction technology and design have enabled the use of lighter, more structurally- and environmentally-efficient materials such as laminated timber 1, 2, 3. However, the increase in popularity of lightweight 5 wooden buildings has been accompanied by raising concerns regarding their vibration behaviour when subjected to dynamic forcing such as footfall actions 4, 5, 6. Given their notable structural efficiency, wooden floors are usually associated with smaller masses than their more conventional counterparts in steel or concrete. This feature, which allows for savings in material, manufacture, transportation, and construction; and leads to further reductions in carbon footprint [1, can also cause undesirable levels of vibration discomfort that compromise the functionality of the building [4, 7, 8].

The unintended dynamic under-performance of timber floors has often led to the use of concrete topping as a means of reducing the perception of vibrations due to dynamic excitations [4, 9, 10. These upgrading measures contravene the lightness and sustainability advantages of timber and can diminish the potential benefits underpinning the use of wood in construction [11. It is therefore imperative to find new solutions that would mitigate the undesirable vibration discomfort associated with timber floors while upholding the advantages of timber as a building construction material.

It is generally accepted that human tolerance to vibration depends on its amplitude and frequency as well as on the type of activity being undertaken [12, 13, 14. While humans have a good sense of movement and balance they appear less able to discern between vibration amplitudes [15] and current codified guidance works well only for highly-conforming scenarios closely matched to situations assumed for code calibration [16]. Research conducted by Lee et al. 17] has found that humans are more sensitive to low-frequency vibration than to high frequencies and that the vibration levels required to trigger human 
sensations which may annoy or distress at low frequencies are typically small, except when particular phenomena like beating take place. Also, while transient oscillation caused by impulsive action is generally well perceived, it is the steady state structural response that has been found to cause most of human 35 discomfort in many cases [18].

The ISO standard [14 defines base relationships between acceptable levels of peak acceleration (root-mean-square) as a function of motion frequency. A modified version of these curves is adopted in the British Standard BS 6472:1992 19] by proposing a series of scaling factors, while Eurocode 5 [20] includes recommendations for the assessment of the vibration serviceability of timber floors with frequencies larger than $8 \mathrm{~Hz}$. Concurrently with the development and updating of codified provisions, the characterization of footfall impacts due to human activity has been extensively investigated [18, 22, 21. The most proba-

45 ble human walking frequencies have been demonstrated to lie in the range of 1.5 - $2.2 \mathrm{~Hz}$ with jogging and running inducing loads with frequencies well above that range 23 . Nonetheless, wooden floors have relatively low fundamental frequencies and are susceptible to modal clustering [5], making them particularly vulnerable to vibration discomfort. In many cases, this does not mean that analyses should be restricted to the lowest modes and any design decision is bound to be case-specific. The peculiarities of the dynamic response of timber floors reinforce the need for a more robust and innovative motion-control strategy.

In this paper, we introduce a motion-control solution that exploits the advantages offered by modern digital design and manufacture in enabling the production of complex structural forms with relative easiness (via CNC machining or $3 \mathrm{D}$ printing). To this end, we propose a new beam configuration that incorporates flexural resonators tuned to key structural frequencies of the flooring 60 system. The resonators are integrated into the body of the beam and the structure is sized to satisfy typical strength and stiffness demands. For concept 
validation, we perform a number of static and dynamic tests on reduced scale specimens on single beams. Further numerical assessments are conducted into the applicability of the proposal to full flooring systems under realistic design scenarios. The results show that, by virtue of their unique geometric arrangement, the proposed beams can effectively reduce the amplitude of the waves propagating through them. Thus, they enhance the vibration comfort compliance of wooden floors. The motion-control capabilities of wooden beams can be further improved by the inherent damping of 3D-printed materials. Practical areas of further research conductive to on-site application of the concept are also highlighted.

\section{Design of beam with integrated resonators}

\subsection{Design concept}

The concept of damping out undesirable modes of vibration by means of carefully tuned oscillators has wide-ranging applications in structural engineering 24. A conventional vibration absorber consists on a mass attached to the main structure via an elastic spring as depicted in Fig. 1a The system uses a one to one correspondence between the forcing frequency $(\Omega)$ and the local resonance frequency of the mass-spring device $\left(\sqrt{k_{a} / m_{a}}\right)$ to transfer the vibration

so energy from the forcing action to the absorber. Thus, reducing the motion of the main structure. Although elastic waves in beams are considered to be dispersive [25], meaning that waves of different wavelengths travel at difference frequencies, the negative effective mass mechanism is still be the major cause of stop-bands (bands of frequencies through which waves are attenuated) in simply-supported beams such as the one depicted in Fig. 1a. This dissipation mechanism leads to the cancellation of the effects of the forcing action by means of the inertial force $\left(F_{a}=-m_{a} k_{a}\right)$ developed in the resonator. Furthermore, since transverse shear forces and bending moments propagate through the beam, both translational and rotational oscillators can be employed to create the required frequency stopbands. 


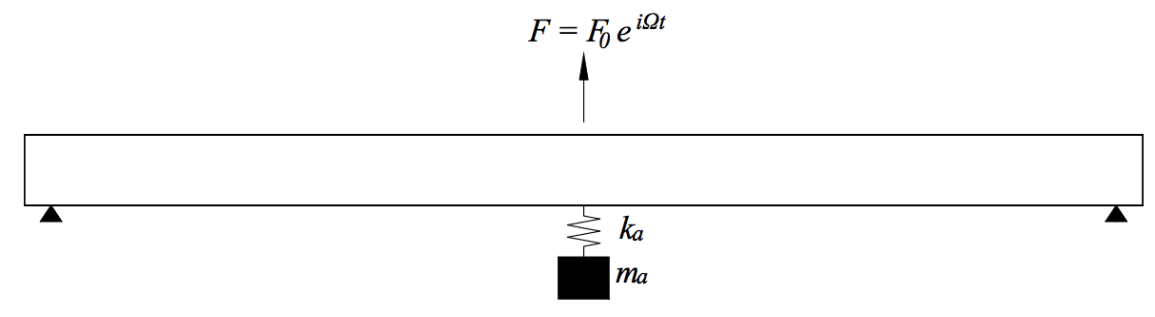

(a) Conventional vibration absorber

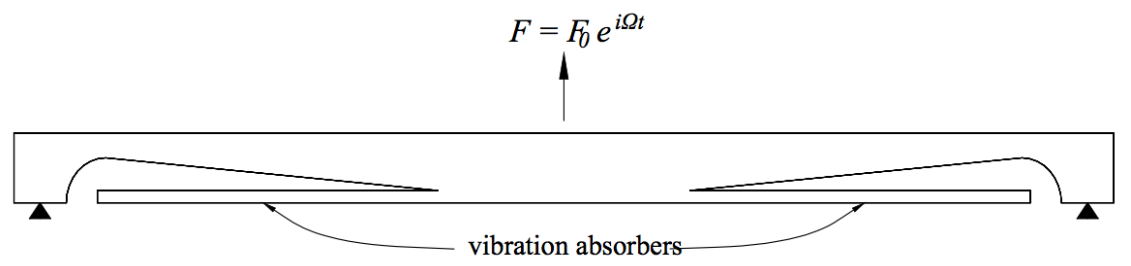

(b) Beam with integrated vibration absorbers

Figure 1: Simply-supported beam with mid-span vibration absorber.

Fig. 1 b presents the beam configuration put forward in this study. A major consideration in the development of the proposed beam layout was the need to provide a resonator of adequate mass and stiffness while avoiding increasing the overall beam's depth or reducing the floor-to-ceiling height. This is achieved by exploiting the flexibility in manufacturing offered by digital design and fabrication. Therefore, a modular simply-supported beam of varying cross section along its main axis is adopted. The beam's depth reduces towards the supports (where flexural and sectional inertia requirements are minimum) ensuring that only enough material as that which is required to resist the corresponding shear forces and bending moments is provided. This sectional depth variation can be easily obtained from the corresponding bending-moment and shear-force diagrams. Besides, the proposed configuration can be easily fabricated by additive or subtractive digital manufacturing processes. The new beam configuration frees up enough space underneath the structural skeleton to place the vibration absorbers. For this purpose, we employ a pair of symmetric auxiliary beams 
cantilevering from mid span to act as resonators. Besides satisfying the original space constraints, the proposed beam configuration with supplemental cantilever resonating beams has the potential of offering multi-frequency vibration control features given the continuous nature of the resonators. Although the dynamic interaction between the beam and suspended ceiling and installations is not accounted for in the analyses that follow, this is not expected to significantly alter the response of the system.

\subsection{Proof-of concept case study}

In order to proof the concept, an 8-metre span beam was selected as a case study. This span was selected in order to highlight the potential benefits for slender elements and other configurations are studied later in the paper. The 3D-printable Woodfill material was employed for the design of all beams presented in this paper. This material is composed of at least $30-40 \%$ wood fibres of potentially recycled material. Recycled wood has well-proven Life Cycle sustainable credentials as demonstrated by various previous studies [26]. The average elastic modulus of the Woodfill material obtained from 3 samples was $E=2.3 \mathrm{MPa}$, while average values of $40 \mathrm{MPa}$ and $1150 \mathrm{~kg} / \mathrm{m}^{3}$ were obtained for the flexural strength along the printing fibres and density, respectively. A $30 \%$ reduction in strength and stiffness for loading perpendicular to the printing fibres is to be expected according to previous studies [27]. These average material properties are comparable to those of other wood-base engineered materials and have been employed in all structural design calculations described below.

A floor layout of 8 by $3 \mathrm{~m}$ was initially assumed with superimposed loads of $5 \mathrm{kN} / \mathrm{m}^{2}$ and $1 \mathrm{kN} / \mathrm{m}^{2}$ for occupancy and partitions, respectively. Due to lack of standarized guidance, the general design principles for timber structures delineated in BS EN 1995-1-1:2004 [20] were followed for this proof-of-concept assessment. We evaluated three alternative designs involving: i) a solid rectangular beam, B1, that serves as basis for our comparisons, ii) a beam with a single pair of resonators targeting the main natural frequency of the floor, 
B2, and iii) a beam with two pairs of resonators targeting a broader band of frequencies, B3. A shallow beam with a span $(L=8 \mathrm{~m})$ to depth $(h=0.65 \mathrm{~m})$ ratio of $L / h \approx 12$ was selected for the solid case (beam B1) to highlight the potential dynamic complexities of shallow floors. For beams B2 and B3, besides deformations constraints, bending action was found to dominate the section depth at all location along the beam, in line with the design concept outlined before. Similarly, a pre-chamber of $10 \mathrm{~mm}$ at mid-span was necessary to satisfy maximum deflection demands. Further concerns regarding stress concentrations that might arise near the supports were mitigated by ensuring a smooth curved transition as shown in Fig. 1b,

For this proof of concept, we have selected a highly regular case in favour of clarity of demonstration. To this end, the selected configuration ignores the effects of irregular plan configurations, non-symmetric floor support conditions, irregular mass distributions, motion transmission and others. Furthermore, it is indeed nearly unmanageable to isolate the effects of those factors in a generalised manner in a single study. However, as stated in the introduction, the definition of actual modal frequencies to be damped out is case-specific by nature and should be assessed individually. This aspect, instead of configuring an insurmountable constraint, should be seen as a window of opportunity for the sort of solutions put forward in this study that rely on digital design and manufacture to provide structural elements with particularly tuned dynamic characteristics, the extensibility of which will be matter of future investigation.

Initial estimates of the vibration frequencies of beams and resonators were obtained by means of Euler-Bernoulli approximations for simply-supported beams:

$$
\omega=(n \pi)^{2} \sqrt{\frac{E I}{\rho L^{4}}}
$$

and free cantilever beams:

$$
\omega=\frac{c}{2 \pi} \sqrt{\frac{E I}{\rho L^{4}}}
$$


where $E$ is the elastic modulus, $\rho$ the mass per unit length, $L$ the beam span, $n$ the mode number, $c$ is a parameter that adopts the values of $c=3.516,22.0345$, or 61.6972 for $n=1,2$ and 3 , respectively, and $I$ the section moment of inertia. In the case of beams B2 and B3 with variable section, $I$ was approximated as [28]:

$$
I=\frac{I_{s}}{\left(\frac{h_{s}}{h_{m}}\right)^{3}\left(\frac{1}{0.15+0.85\left(\frac{h_{s}}{h_{m}}\right)}\right)}
$$

where $I_{s}$ is the second moment of area of the shallower beam section, $h_{s}$ the smaller beam depth and $h_{m}$ the beam depth at mid-span.

After a preliminary sizing of the elements, a series of numerical analyses were performed to fine-tune the design. To this end, we constructed a series of finite-element models in the open-source Finite Element framework OpenSees [29]. Fig. 2 shows an example of a typical FE model adopted. The varying cross section of the beam was approximated by a series of Elastic Timoshenko Beam elements. Likewise, Elastic Timoshenko Beam elements of constant cross section were adopted for the vibration absorbers. In order to maintain the mass consistency between the numerical model and the prototype design, additional nodal masses were employed together with the specified mass density in each uniform element. As an initial approximation, $2 \%$ critical viscous damping was assumed in the numerical analyses to obtain generalizable comparisons for systems joined by means of mechanical fasteners 30. Besides, no interaction between the slab and the beam was considered at this initial stage with only the corresponding mass being accounted for. The implications of slab-beam interactions are considered in the parametric studies presented later in this paper. sions presented above were employed as the starting dimensions of the numerical models for beams B2 and B3. Beam B1 corresponds to a traditional rectangular beam design and its dimensions were set based solely on conventional strength and stiffness (serviceability) considerations. In the case of beam B2, our goal 


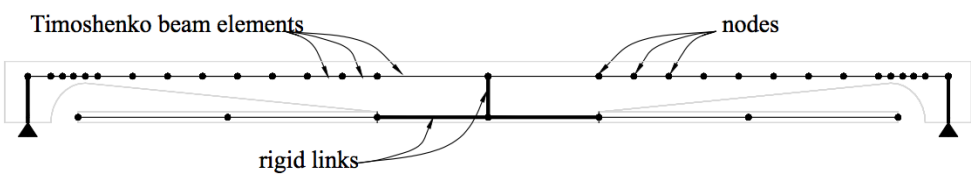

Figure 2: Finite element model of B2. impact between the resonators and the top part of the beam occurred under normal dynamic actions. Scaled versions of these beams were manufactured (Fig. 4) and tested as described in the next section. 


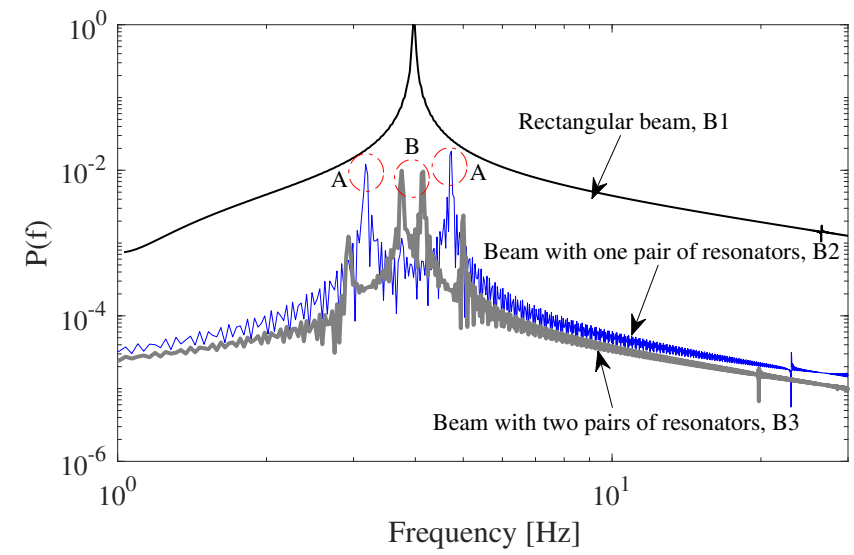

Figure 3: Normalized frequency response of alternative beam designs.

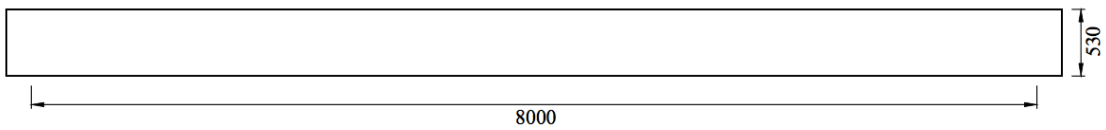

(a) B1, solid rectangular beam.

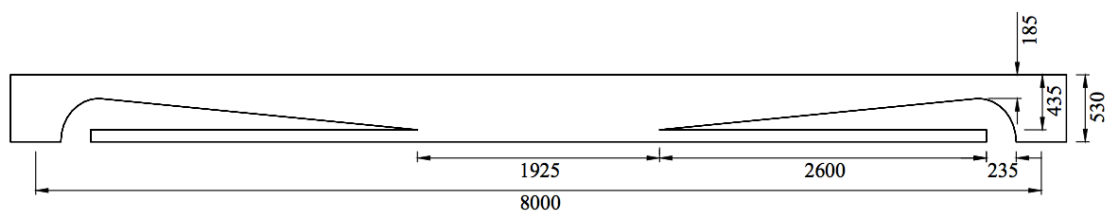

(b) B2, beam with a single pair of integrated resonators.

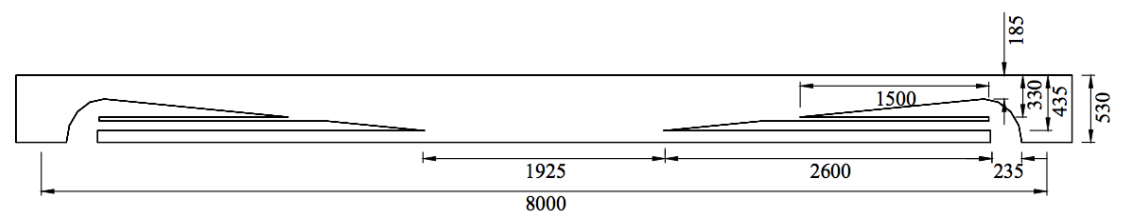

(c) B3, beam with two pairs of integrated resonators.

Figure 4: Beam design prototypes (dimensions in $\mathrm{mm}$ ). 


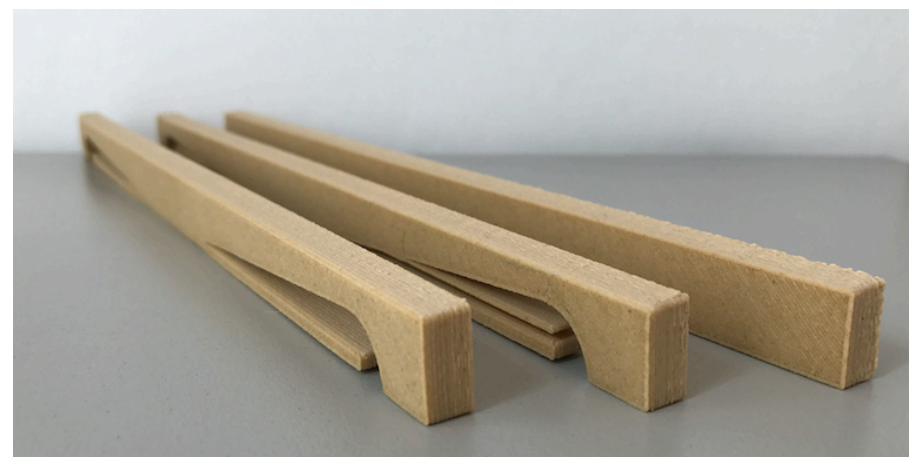

Figure 5: 3D-printed specimens.

\subsection{Test set-up and specimen details}

A prototype of each beam described in the previous section was fabricated by fused deposition at a scale of 1:30. This scale obeys to practical commercial 3D printing constraints leading to a frequency scaling of 30x due to similitude laws. beam printing, the samples were tested under free-vibration and monotonically increasing static forces. The results of the static tests are presented first in the next section followed by their vibration response characterization.

\subsection{Static response}

220 in Fig. 6a. This test configuration provided an independent confirmation of the material properties assumed in the design and served to verify the ultimate response of the new beam designs. To this end, the mid-span displacement was increased at a rate of $0.03 \mathrm{~mm}$ per second until failure. Fig. 6b presents the normalized force-displacement relationships for beams B1 and B2, with and without the resonators, respectively. The curves are normalized to the yield point of beam B2. The design load corresponds to a value of around $\approx 0.6$ in normalized terms. The response of Specimen B3 follows closely that of B2 in Fig. 6b. The slightly stiffer response of the solid beam is caused by the 


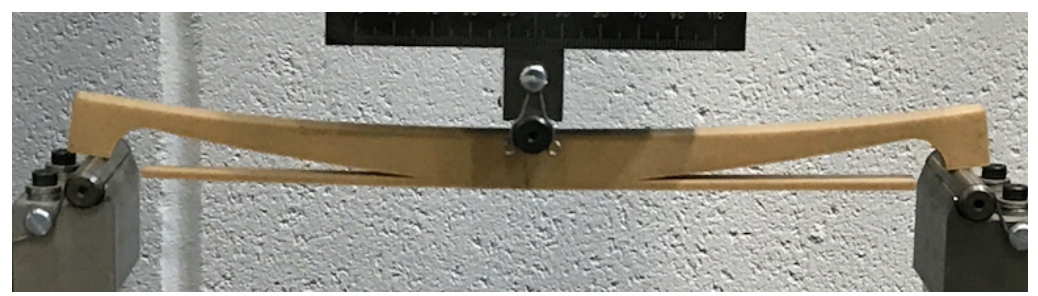

(a) Static test on specimen B2.

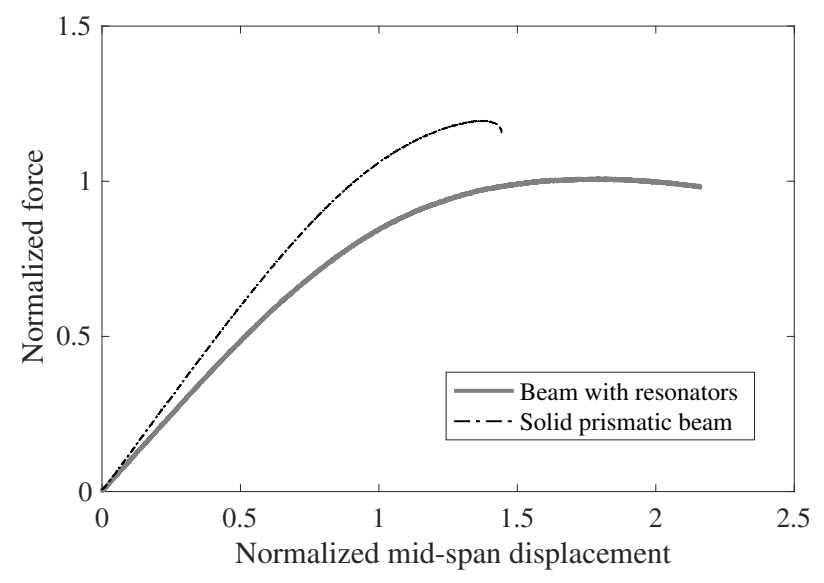

(b) Force-displacement relationships.

Figure 6: Static tests.

larger flexural stiffness of a constant section throughout in comparison with the tapered design. Nevertheless, the beams with resonators is able to resist forces up to $40 \%$ larger than the imposed design loads with larger ductilities (i.e. higher ratios between ultimate deformation versus deformation at yield). The optimized shape of Specimen B2 lead to profuse yielding of the material 235 along the beam's length although fracture was not reached during testing. On the contrary, the conventional configuration of beam B1 lead to a brittle failure immediately after failure, albeit with an over-strength of nearly $60 \%$. 


\subsection{Dynamic response} proposed, we carried out a series of dynamic characterization tests on the same specimens described above. The purpose of these tests was not to provide exact design or expected acceleration values but to experimentally verify the effectiveness of the dynamic absorbers with the unconventional configuration suggested ology 31 was applied in all beams and the results are reported in Figure 7 The beams were vertically restrained at their extremes and two accelerometers were employed. One accelerometer was attached at the beam mid-span while a second accelerometer was employed to record the vertical accelerations at the in terms of accelerance (acceleration over force) when the hammer impacted at points A and B, respectively. A minimum of 10 impact tests were carried out to ensure repeatability and the coefficient of variation associated with the peak transmitted force was around 0.27 .

260

It is evident from Figure $7 \mathrm{~b}$ that the beam with a single pair of resonators (Specimen B2) is successful in damping out the vibrations around the targeted frequencies. Furthermore, the peak observed at $170 \mathrm{~Hz}$ for Beam B1 corresponds well to its first vibration mode (accounting for the scale effects of 1:30) whereas

support the test procedure and set-up employed.

When the beam is excited by impact loading at Point B (Figure $7 \mathrm{c}$ ), the results are less clear. This may be due to the presence of higher modes being 


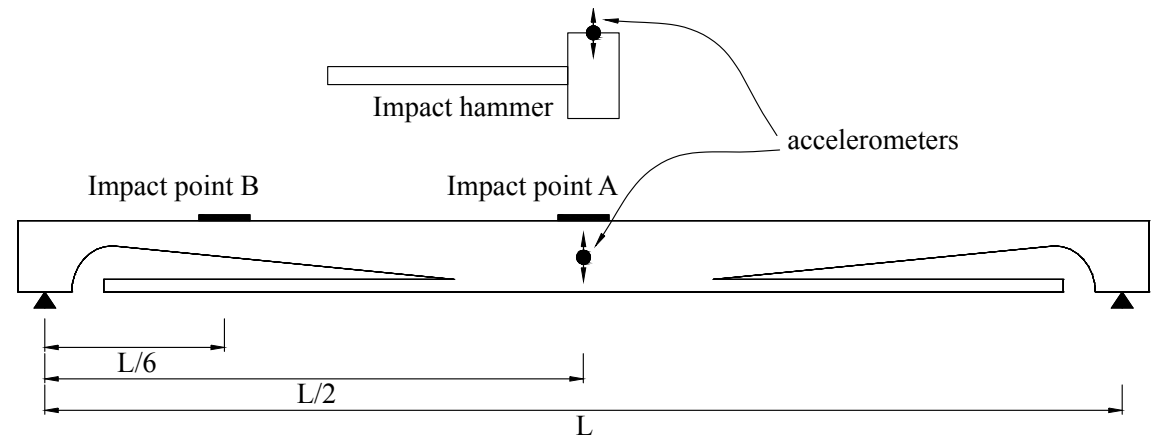

(a) Test set-up.

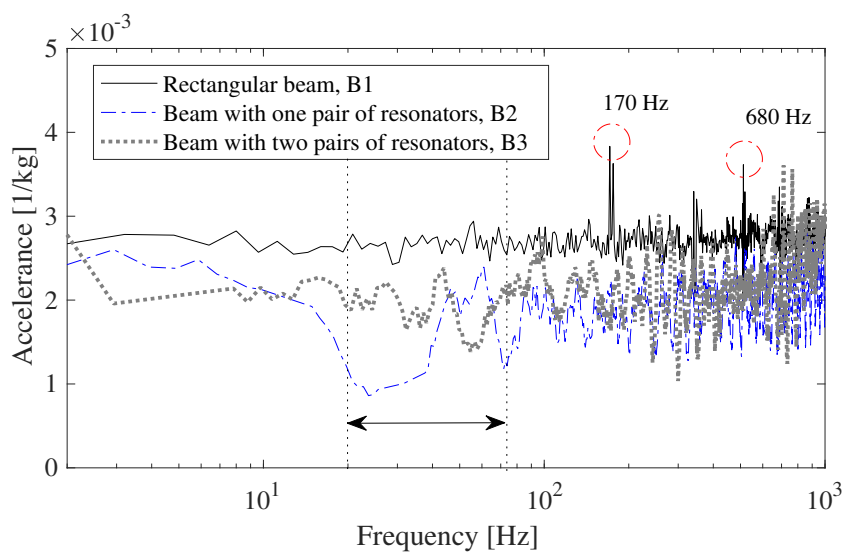

(b) Accelerance at mid-span when using the hammer impact at Point A.

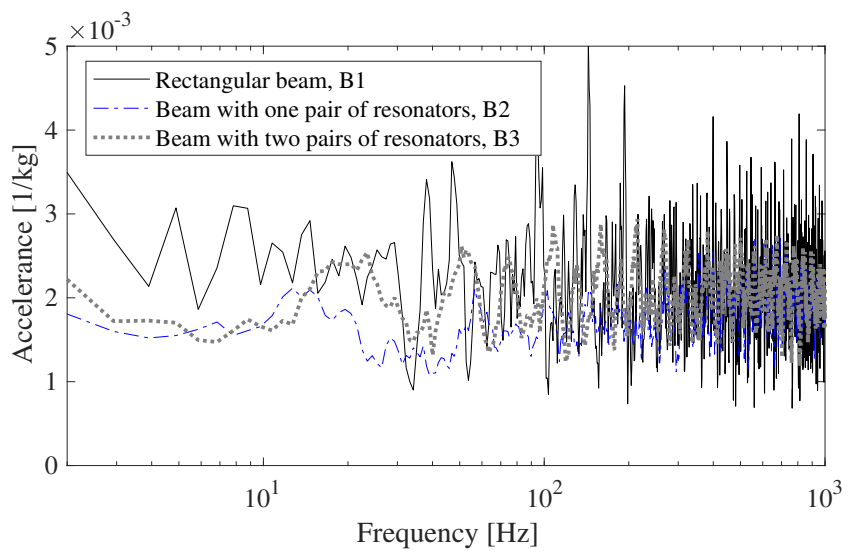

(c) Accelerance at mid-span when using the hammer impact at Point B.

Figure 7: Dynamic proof-of-concept tests. 
270 significant amplitude peaks around the main modal frequencies are reduced in Beam B3 (with two pairs of resonators), its overall performance is far less impressive than that of beam B2 in both Figures $7 \mathrm{~b}$ and $7 \mathrm{c}$. This can be further examined with reference to simplified dynamic models. To this end, insights 275

beams with attachements using the extended Hamilton principle, $\int(\delta T-\delta \Pi+$ $\delta W) d t=0$, where $T, \Pi$ and $W$ are the kinetic energy, elastic energy and external work, such that [32]:

$$
\begin{gathered}
\delta T=\int\left(\rho A \ddot{v} \delta v+\rho I \ddot{v}^{\prime} \delta v^{\prime}\right) d x-m \ddot{u} \delta u \\
\delta \Pi=\int E I v^{\prime \prime} \delta v^{\prime \prime} d x+k\left(u-v_{0}\right)\left(\delta u-\delta v_{0}\right) \\
\delta W=E I v_{1}^{\prime \prime} \delta v_{1}^{\prime}+\left(\rho I v_{1}^{\prime}-E I v_{1}^{\prime \prime \prime}\right) \delta v_{1}-E I v_{-1}^{\prime \prime} v_{-1}^{\prime}+\left(E I v_{-1}^{\prime \prime \prime}-\rho I \ddot{v}_{1}^{\prime}\right) \delta v_{-1}
\end{gathered}
$$

where $A$ is the beam's cross sectional area, $\rho$ the density of the material, $v$ the vertical coordinate, $x$ the horizontal coordinate, $m$ the mass of the attached vibration absorber, $k$ its stiffness, and $u$ its relative displacement. Therefore:

$$
\begin{gathered}
\rho A \ddot{v}-\rho E I \ddot{v}^{\prime \prime}+E I v^{i v}+\left[E I\left(v_{0}^{\prime \prime \prime}-v_{0-}^{\prime \prime \prime}\right)+k\left(v_{0}-u\right)\right] \delta(x)=0 \\
m \ddot{u}+k\left(u-v_{0}\right)=0 \\
E I\left(v_{0-}^{\prime \prime}-v_{0+}^{\prime \prime}\right)=0
\end{gathered}
$$


Assuming a beam's width and length of $B$ and $L$, respectively, and considering the wave number, $\beta$, and frequency, $\omega$, the following equivalent mass, $\bar{m}$, and stiffness, $\bar{k}$, can be calculated:

$$
\begin{gathered}
\bar{m}=\frac{2 \rho A \sin (B L / 2)}{\beta} \\
\bar{k}=2 E I \beta^{3} \sin (B L / 2)
\end{gathered}
$$

leading to the dispersion equation:

$$
\left[\omega^{4}-\left(\frac{k}{m}+\frac{k}{\bar{m}}+\frac{\bar{k}}{\bar{m}}\right) \omega^{2}+\frac{k}{m} \frac{\bar{k}}{\bar{m}}\right]=0
$$

Equation 12 defines the relationship between travelling waves of different length, as characterized by their wave number, and their corresponding frequencies, $\omega$. Figure 8 plots such relationships for Beam B2 assuming the mechanical properties defined in Equations 1 and 3 . The theoretical dispersion curves for Beam B2 depict a clear stop band in the region of 35 to $95 \mathrm{~Hz}$ in the scaled beam, corresponding to 1.1 to $3.2 \mathrm{~Hz}$ in a full-size beam. This frequency band largely coincides with the experimentally observed depression in amplitude magnitudes depicted in Figure 7b. These phenomena is difficult to model with standard finite element formulations which will require prohibitive levels of discretization in order to depict wave propagation phenomena [33]. Conversely, in the case of Beam B3, the spectral analysis is complicated by the interaction between the resonators themselves potentially leading to the annihilation of any beneficial stop band as expressed in the experimental results. Therefore, targeting two response peaks may require a more involved design model and approach than the one followed above.

\section{Implementation studies}

The results and discussion offered in the preceding sections have proved the feasibility of incorporating effective vibration absorbers within typical beam 


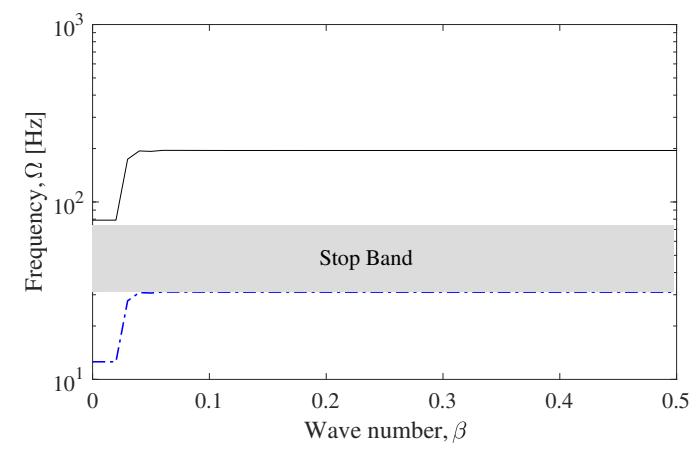

Figure 8: Dispersion curves for Beam B2.

depth ratios through the manufacture of an optimized beam shape by means of additive (or subtractive) digital processes. It is important to note that the tuning of the resonators ought to be done with respect to the characteristics of the flooring system and not the individual beam response. Therefore, this section, will extend the numerical analysis to typical timber flooring configurations under usual design loading conditions. To this end, dead and live loads as well as timber slabs are incorporated into our numerical models and a parametric analysis is performed under typical design dynamic footfall action. These explorations will further evaluate the effectiveness of the proposed design under realistic conditions and uncover areas requiring future attention.

\subsection{Numerical models}

A series of numerical models were constructed in the comercial Finite Element software Oasys GSA [34] comprising $8 \mathrm{~m}$ by $8 \mathrm{~m}$ and $3 \mathrm{~m}$ by $8 \mathrm{~m}$ flooring slabs incorporating timber beams with and without flexural resonators. These floor layouts were selected as representative of the typical boundaries encountered in building structures. Figure 9 depicts the FE models with vibration absorbers. Linear beam elements were employed for the beams with an average discretization of around 27 elements per member. Cross-laminated timber (CLT) slabs were considered in all cases and modelled by means of shell elements with effective properties to reflect their anisotropy. Average CLT slab 


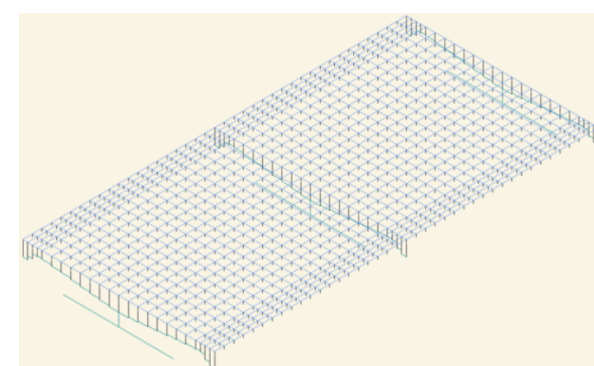

(a) $8 \mathrm{~m}$ by $8 \mathrm{~m}$ arrangement.

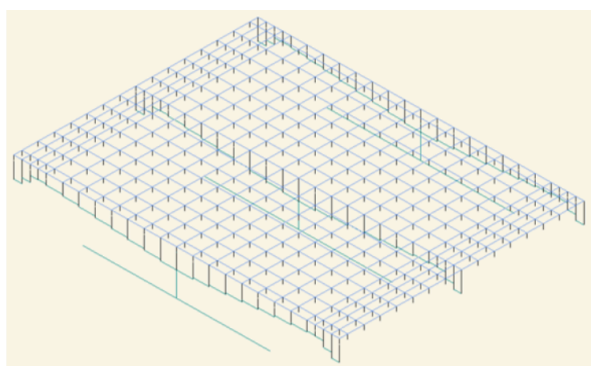

(b) $3 \mathrm{~m}$ by $8 \mathrm{~m}$ arrangement.

Figure 9: Floor models from Oasys GSA GUI 34, not drawn to scale.

thicknesses of $200 \mathrm{~mm}$ with 5 layers were employed in line with current design proposals [35. As with previous models, rigid links were used to attach the resonators at centreline distances. The Glulam beams were connected to the CLT slabs through nodal links. The shear stiffness of these links was varied to cover the ideal bounding cases of full-composite action and no composite action (i.e. CLT slab resting on Glulam beams).

Nominal material properties were assumed for the timber elements [36. To this end, an Elastic Modulus of $12 \mathrm{GPa}$ and a density of $=400 \mathrm{~kg} / \mathrm{m}^{3}$ were employed for the timber. A reduced bending stiffness was calculated to account for the CLT layer directionality by means of the following expressions:

$$
\begin{gathered}
E I_{C L T, \text { eff }}=\sum E I_{C L T}+\gamma E A z^{2} \\
\gamma=\left[1+\frac{\pi^{2} E_{i} A_{i} h_{i}}{b G_{r} l^{2}}\right]^{-1}
\end{gathered}
$$

where $E_{i}, A_{i}$, and $h_{i}$ are the Elastic Modulus, Area, and height of the i-th CLT layer, respectively, and $b$ and $l$ their width and length.

The floors were designed to follow Eurocode 5 [20] design principles of serviceability and strength. Life occupancy and partitions loads of $5 \mathrm{kN} / \mathrm{m} 2$ and 1 $\mathrm{kN} / \mathrm{m} 2$ were considered, respectively Also, a deflection limit of $1 / 200$ in terms 
of floor span was employed for serviceability checks. An effective $10 \%$ contribution of live loads was employed for the dynamic analysis. The numerical models constructed as described above were employed to fine-tune the design to an optimal solution with the resonators targeting the main frequency of the flooring system. Importantly, the beam depth to span ratios obtained were in the order of 0.08 to 0.15 , which are in line with values observed in practice. Moreover, the resonator thickness varied between 10 and $15 \mathrm{~cm}$ which are easy to accommodate in typical building projects.

We used the footfall analysis features of GSA to evaluate the vertical (out of plane) response of the floors due to walking activities. Footfalls generally consist of series of periodic loads with further harmonic subcomponents. Following current industrial practice, and with the help of GSA, we first performed a modal analysis on or floor models including all self-weight plus $10 \%$ of the live loads. The common practice of assessing the structural behaviour to footfall actions with up to 4 harmonics was followed covering all frequencies up to $10 \mathrm{~Hz}$ with a main walking frequency in the range of 1.0-2.5 Hz. In order to perform footfall analyses, GSA generates harmonic loads over the defined frequency range and calculates the model response for each case by means of modal analysis in conjunction with a Square Root Sum of the Squares (SRSS) combination. The full excitation method was selected, meaning that all nodes were excited leading to a more rigorous approximation. Similarly, we specified the walking on floor Arup method 34 to define the excitation with the number of footfalls equal to the length of the floor divided by the footstep length.

\subsection{Results}

Figures 10 and 11 summarize the results of the parametric analyses in terms of response spectra for the $8 \mathrm{~m}$ by $8 \mathrm{~m}$ and $3 \mathrm{~m}$ by $8 \mathrm{~m}$ configurations. The output of modal footfall analysis is expressed in terms of response factors, denoting the ratio of the modal response against the corresponding value of the 


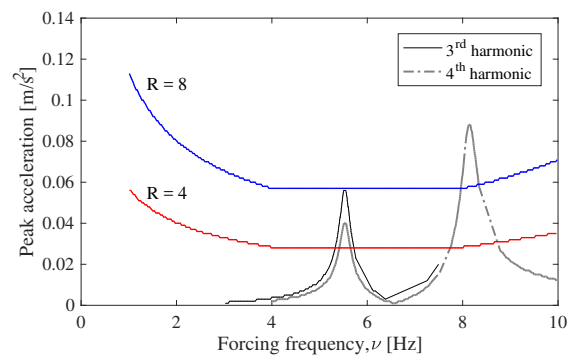

(a) Without resonators, non-composite action.

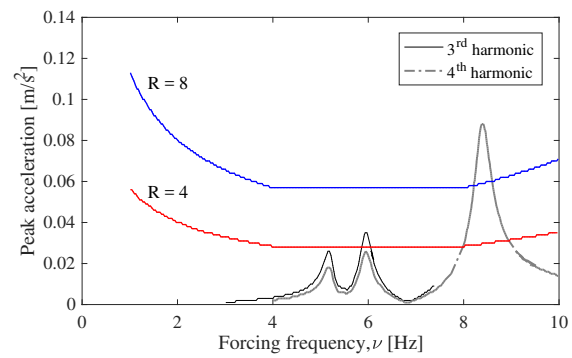

(c) With resonators, non-composite action.

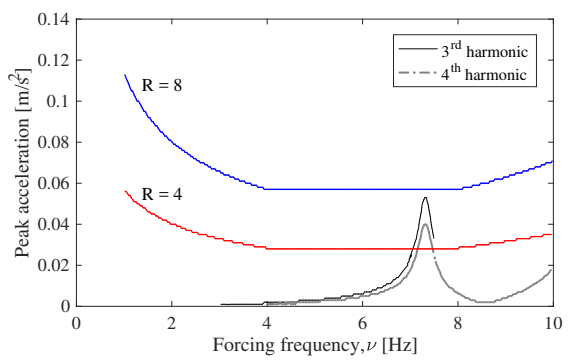

(b) Without resontators, composite action.

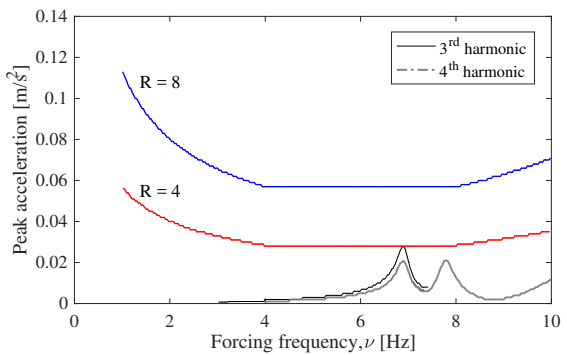

(d) With resontators, composite action.

Figure 10: Footfall analysis for the 8 by $8 \mathrm{~m}$ configurations.

base acceleration, along a frequency range. The blue and red lines (top and bottom respectively) indicate a constant level of discomfort and represent a response factor of 8 and 4 , respectively. Although the response factors limits vary strongly depending upon the building purpose, it is generally preferable to aim for response factors lower than 8 [19]. Figures 10 and 11 clearly indicate that the first harmonic not always generates the greatest occupant discomfort. Instead the third and fourth harmonics produce higher peak accelerations in all cases.

It can be appreciated from Figures 10 and 11 that the new design incorporating flexural resonators has effectively reduced peak accelerations in all floor systems considered (Figures 10c \& 10d and 11c \& 11d) in comparison with the use of prismatic beams (Figures 10a \& 10b and 11a \& 11b), specially for lower modes. However, some differences in the dynamic behaviour of non-composite 

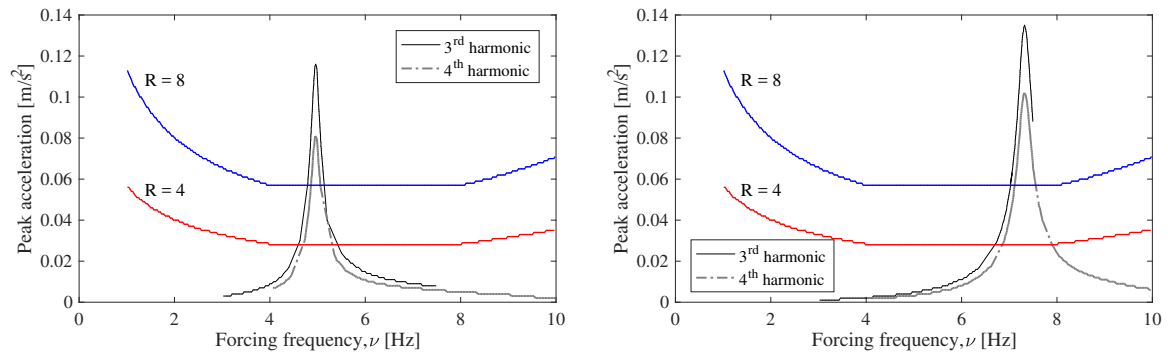

(a) Without resonators, non-composite action.

(b) Without resontators, composite action.

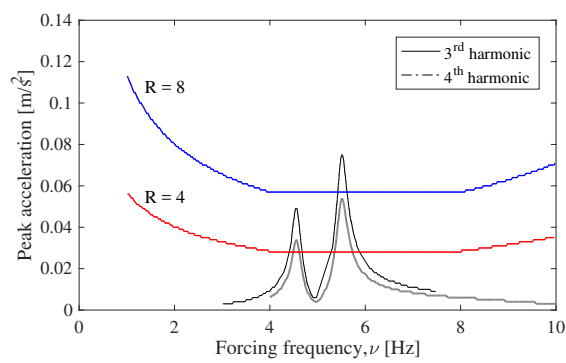

(c) With resonators, non-composite action.

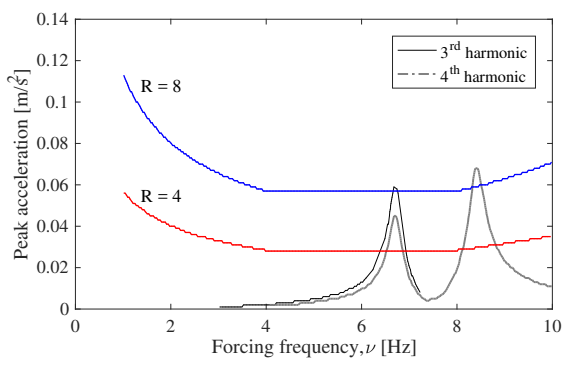

(d) With resontators, composite action.

Figure 11: Footfall analysis for the 3 by $8 \mathrm{~m}$ configurations. 
full-composite slabs are generally significantly stiffer in bending due to the rigid joint between beams and CLT. Therefore, they often have their fundamental mode at a higher frequency which makes them less prone to walking induced vibrations, since only the third or fourth harmonic falls within these frequency ranges. In this case, the resonators are effective in reducing peak acceleration close to within acceptable limits as it can be seen in both floor layouts.

On the other hand, non-composite slabs are considerably less stiff and therefore exhibit a lower frequency mode. As a consequence, the second harmonic plays a more prominent role in the response of these flooring systems, especially in the non-composite $3 \times 8$ layout, which makes the vibration attenuation more difficult. It is worth noting that although non-composite construction may lead to reductions in labour and connector costs, it is also associated with larger beam sections and the benefits of composite action quickly offset those of non-composite configurations. Overall, the results of the dynamic analyses presented herein support the dynamic effectiveness of the new beam configurations to enhance the dynamic comfort in timber buildings.

\subsection{Issues for further assessment}

The main aim of this paper is to put forward and proof the a new wooden beam design concept under typical building constraints. This has been achieved through the experimental, numerical and parametric analyses presented in the previous section. However, a number of issues need to be tackled before gaining enough confidence leading to a widespread adoption of the proposed designs. To start with, although the beam shape can be formed by material removal (e.g. CNC cutting), the use of 3D printing at large scales will bring forth higher 405 damping ratios with the potential benefits of improved response reduction and broadening of the frequency band for which the resonators are effective. To this end, new beam configurations and multi-material configurations should be explored. The quantification of the environmental benefits of using recycled wood into the extruded material are also important, as is the evaluation of long-term 
incorporating a full description of the variability in loading and material are essential and may yield target frequencies other than the main to be accounted for. All these are areas of future and ongoing research.

\section{Conclusion}

timber flooring systems while retaining the original environmental benefits of wood in construction was presented. To this end, we carried out finite element simulations, small scale experiments, and design-oriented parametric analyses. Our studies support the following conclusions:

420
- The feasibility of a new beam configurations that incorporates flexural resonators integrated into the main body of the beam satisfying typical building strength and stiffness demands was examined.

- The dynamic effects of the flexural resonators, tuned to key structural frequencies of the system, can lead to significant reductions in the vibration levels of the floor.

- The vibration comfort enhancements brought about by the new design are greater in floors with full composite action between beams and slab than in those where the shear connectivity between the wooden beams and the CLT slabs is negligible.

- The incorporation of two (instead of one) pairs of resonators leads to a highly complex dynamic behaviour that, at this stage, seems less effective in comparison with tuning a pair of resonators to a single floor frequency.

- Although the concept is generally applicable to other building materials, it is particularly suited for timber floors where the advantages of digital manufacture (e.g. additive or subtractive) are already being exploited. Furthermore, the concept put forward retains the lightweight advantages 
of timber avoiding the provision of additional supplemental mass in the form of less-sustainable materials like concrete toppings.

Finally, it is worth noting that the definition of target modal frequencies to

440 be damped out is case-specific by nature and should be assessed individually, and that some higher vibration modes affecting the flooring system may be more difficult to control through resonating beams than others. This case specificity favours the use of solutions that capitalize on the bespoke nature of digital design and manufacture technologies to create dynamically robust solutions.

\section{References}

[1] Asdrubali F, Ferracuti B, Lombardi L, Guattari C, Evangelisti L, Grazieschi G. A review of structural, thermo-physical, acoustical, and environmental properties of wooden materials for building applications. Building and Environment, 114: 307-332, 2017.

[2] Ceccotti A. New technologies for construction of medium-rise buildings in seismic regions: the XLAM case. Struct Eng Int 18(2):15665, 2008.

[3] Smith I, Frangi A. Structural use of timber in tall multi-storey buildings. Structural engineering document. 13. Zurich, Switzerland: International Association for Bridge and Structural Engineering, p. 191, 2014.

[4] Skinner J, Martins C, Bregulla J, Harris R, Paine K, Walker P, Dias A. Concrete upgrade to improve the vibration response of timber floors. Proc. ICE Structures \& Buildings, 559556, 2014.

[5] Ussher E, Arjomandi K, Weckendorf J, Smith I. Prediction of motion responses of cross-laminated-timber slabs. Structures, 11:49-61, 2017.

[6] Trada Technology. Cross-laminated timber (Eurocode 5) design guide for project feasibility. Timber engineering guidance document GD 10. High Wycombe, UK: TRADA Technologies; 2009. 
[7] Hu L. Serviceability of next generation wood buildings: laboratory study of vibration performance of cross-laminated-timber (CLT) floors. Project 301006159: report 2012/13. Sainte Foy, Quebec, Canada: FPInnovations, 2013.

[8] Cross laminated timber - a competitive wood product for visionary and fire safe buildings. In: Falk A, Dietsch P, Schmid J, editors. Proceedings of the Joint Conference of COST Actions FP1402 and FP1404, SP report 2016:41. Boras, Sweden: SP Technical Research Institute of Sweden, 2016.

[9] Ceccotti A. Timberconcrete composite structures. In Timber Engineering, STEP 2 (Blass HJ, Aune P, Choo BS et al. (eds)). Centrum Hout, Westeinde, the Netherlands, E13/1 E13/12, 1995

[10] Toratti T, Kevarinma A. Development of wood-concrete composite floors. IABSE Symposium Report 85(2):2530, 2001.

[11] Nasse J, Hedenus F, Karlsson S, Holmberg J. Concrete vs. wood in buildings - an energy system approach, Building and Environment, 361-369, 2012.

[12] Polensek A. Human response to vibration of wood joisted floors. Wood Sci, 3:111119, 1970.

[13] Ohlsson SV. Springiness and human induced floor vibration: a design guide. Document no. D-12. Stockholm, Sweden: Swedish Council for Building Research, 1988.

[14] International Organization for Standardization (ISO). Evaluation of human exposure to whole-body vibration Part 2: continuous and shock-induced vibration in buildings (1 to $80 \mathrm{~Hz}$ ), Standard 2631-2. Geneva, Switzerland: ISO, 1989.

[15] Smith AL, Hicks SJ, Devine PJ. Design of floors for vibration: A new approach. Steel Construction Institute Ascot, UK, 2007. 
[16] [Hu L, Chui YH. Development of a design method to control vibrations induced by normal walking action in wood-based floors. Proceedings of 8th World Conference on Timber Engineering, Lahti, Finland. vol. 2., 2004.

[17] Lee PJ, Lee BK, Griffin MJ. Evaluation of floor vibrations induced by walking in reinforced concrete buildings. Internoise, Innsbruck, Austria, 2013.

[18] Murray T, Allen D, Ungar E. Floor vibrations due to human activity. American Institute of Steel Construction, Steel Design Guide Series, 11. Second Edition, 2003.

[19] BS 6472:1992. Guide to evaluation of human exposure to vibration in buildings. BS 6472:1992, 1992.

[20] CEN. Comite Europeen de Normalisation, EUROCODE 5 - design of timber structures, part 11: general common rules and rules for buildings. EN 1995-1-1:2004 (E), English version. London, UK: British Standards Institution, 2004.

[21] Zivanovic S, Pavic A, Reynolds P. Vibration serviceability of footbridges under human-induced excitation: a literature review. Journal of Sound and Vibration, 279(12):174, 2005.

[22] Applied Technology Council (ATC). ATC guide on floor vibration, Redwood City, CA, USA. 1999; 1999.

[23] Ji T, Pachi A. Frequency and velocity of people walking. Structural Engineer. 84 (3), 36-4, 2005.

[24] Connor JJ, Klink BSA. Introduction to Motion Based Design, Computational Mechanics Publication, ISBN:1-85312-454-0, 1996.

[25] Clough RW, Penzien J. Dynamics of structures, 2nd edition, McGraw-Hill, New York, ISBN 0-07-011394-7, 1993. 
[26] Asdrubali B, Ferracuti L, Lombardi C, Guattari L, Evangelistia G, Grazieschi F. A review of structural, thermo-physical, acoustical, and environmental properties of wooden materials for building applications. Building and Environment, 114: 307-332, 2017.

[27] Mueller J, Shea K. The effect of build orientation on the mechanical properties in inkjet 3D-printing. International Solid Freeform Fabrication Symposium, Austin, TX,2015.

[28] Piazza M, Tomasi R, Modena R. Strutture in legno, Ulrico Hoepli Editore, ISBN 978-88-203-3583-0, Italy, 2014.

[29] McKenna F, Fenves GL, Scott MH. Open System for Earthquake Engineering Simulation, Pacific and Earthquake Engineering Research Center, University of California at Berkeley, 2000.

[30] Reynolds T, Harris R, Chang W-S. Viscoelastic embedment behaviour of dowels and screws in timber under in-service vibration. European Journal of Wood and Wood Products 71 (5):623-634, 2013.

[31] Howard C. An inexpensive DIY impact hammer for vibration analysis of buildings, Acoustics Australia, 33(1), 13-18, 2005.

[32] Pai F, Peng H, Jiang S. Acoustic metamaterial beams based on multifrequency vibration absorbers. International Journal of Mechanical Sciences, 79:195-205, 2014.

[33] Kausel E. Can a discrete dynamic model ever perfectly simulate a continuum? Soil Dynamics and Earthquake Engineering, 112: 53-57, 2018.

[34] Oasys GSA. Users Manual. Arup, London, UK. Available from: http://www.oasys-software.com/ (last accessed December 2017).

[35] Skidmore, Owings and Merrill. Timber Tower Research Project. 2013. Available from: http://www.oasys-software.com/ (last accessed December $540 \quad 2017)$. 
[36] KLH. Cross Laminated Timber. 2012. Available from: http://www.klhuk.com/media/ (last accessed December 2017). 